Buletin JSJ, 1 (2), 2019, 88-101

Available online di: http://ejournal-balitbang.kkp.go.id/index.php/JSJ/index

\title{
ANALISA PENGGUNAAN BIOSOLAR (B20) DALAM KINERJA SISTEM BAHAN BAKAR DI KAPAL PENGAWAS (KP) ORCA 02
}

\section{ANAL YSIS OF USE OF BIOSOLAR (B20) IN FUEL SYSTEM PERFORMANCE IN ORCA 02 SURVEILLANCE SHIP}

\author{
Pundi Ramadhan Sudrajat ${ }^{1}$, Nurrul Hidayad ${ }^{1}$ Bambang Mutiyoso Gunawan ${ }^{1}$, I Ketut Daging ${ }^{1}$ \\ 1Prodi Teknologi Penangkapan Ikan Sekolah Tinggi Perikanan \\ JI. AUP No. 1 Pasar Minggu-Jakarta Selatan; Telepon +21-7805030 Jakarta 12520
}

Email : hidayadnurrul508@gmail.com

\begin{abstract}
ABSTRAK
Pemerintah menerapkan kebijakan penggunaan biosolar B20 berdasarkan Permen ESDM No. 41 Tahun 2018 tentang Penyediaan dan Pemanfaatan Bahan Bakar Nabati (BBN) Jenis Biosolar dalam Kerangka Pembiayaan oleh Badan Pengelola Dana Perkebunan Kelapa Sawit (BPDPKS). Tujuan dari penelitian ini adalah mengevaluasi efek penggunan B20 pada KP. Orca 02 berpengaruh terutama pada filter catridge dan fuel filter mengalami penurunan kemampuan mengumpulkan kontaminan. Dengan demikian perlu dilakukan penanganan khusus berupa cleaning dan dipasangkan mesin purifier untuk membersihkan kotoran pada tangki agar kualitas bahan bakar optimal. Cleaning dilakukan pada tangki induk dan tangki harian. Pemasangan mesin purifier dengan merek GEA model OSE 5-91-037/5. Berdasarkan pengujian laboratorium kandungan B20 sebelum masuk purifier dan hasil keluaran purifier, perbedaan parameter sendimen dari $0,006 \%$ wt ke $0,005 \%$ wt, dan kadar condradson carbon residu on $10 \%$ distilate residu $0,21 \%$ wt melebihi dari ketentuan. $0,1 \%$ wt. Penanganan khusus berpengaruh terhadap penggantian filter catridge,
\end{abstract}

Kata Kunci : Biosolar (B20), purifier , filter catridge dan fuel filter

\section{ABSTRACT}

The Government is implementing a policy on using Biosolar B20 based on Ministerial regulation ESDM number 41 year 2018 on the provision and utilization of biofuel (BBN) types of biodiesel in the framework of financing by the Agency for Palm Oil Plantation Fund (APOPF). The use of B20 effect on KP. Orca 02 particularly influential in Catridge filters and fuel filters has decreased contaminant collecting ability. So, there is a special handling in the form of cleaning the tank to reduce dirt on the tank as well as the purifier machine to clean the dirt in the tank for optimal fuel quality. Cleaning is done on the mains tank and the daily tank. Installation of the Purifier machine with brand GEA model OSE 5-91-037/5. Based on a lab test B20 content before the purifier and the result of the purifier output, the difference of the parameter of 0,006\% wt to $0,005 \%$ wt, and the level of Condradson carbon residue on $10 \%$ distilate residue $0.21 \%$ wt exceeds the max provisions. $0.1 \% \mathrm{wt}$. Special handling affects the cartridge filter replacement

Keywords: Biosolar (B20), purifier, Catridge filter and fuel filter.

\section{PENDAHULUAN}

Minyak bumi merupakan sumber energi utama dan sumber devisa negara. Namun demikian, cadangan minyak bumi yang dimiliki Indonesia jumlahnya terbatas. Oleh karenanya berbagai upaya telah dilakukan untuk mencari bahan bakar alternatif yang memiliki sifat dapat diperbaharui (renewable) dan ramah lingkungan. Potensi energi yang terbarukan antara lain tenaga matahari, panas bumi, angin, tanaman penghasil minyak dan sebagainya. 


\section{Buletin JSJ, 1 (2), 2019, 88-101}

Available online di: http://ejournal-balitbang.kkp.go.id/index.php/JSJ/index

Indonesia saat ini dalam kondisi darurat energi karena terus menurunnya produksi minyak mentah dan terus naiknya kebutuhan bahan bakar minyak (BBM) masyarakat. Akibatnya kebutuhan impor BBM terus meningkat. Produksi BBM rata-rata tiap bulan (data Kementerian ESDM) hanya sebesar 778.505 barrels oil per day (BOPD). Sementara, kebutuhan BBM sudah mencapai sekitar 1.600 BOPD. Jadi, untuk memenuhi kebutuhan BBM dalam negeri, Pertamina harus mengimpor lebih dari 800.000 BOPD.

Pemerintah menerapkan kebijakan penggunaan biosolar B20 berdasarkan Permen ESDM No. 41 Tahun 2018 tentang Penyediaan dan Pemanfaatan Bahan Bakar Nabati (BBN) Jenis Biosolar dalam Kerangka Pembiayaan oleh Badan Pengelola Dana Perkebunan Kelapa Sawit (BPDPKS). Sehingga pemerintah mewajibkan penggunaan B20 untuk transportasi darat dan transportasi laut.

Biosolar merupakan jenis bahan bakar alternatif yang dapat diperbaharui dan ramah lingkungan karena dari minyak nabati yang kemudian diubah menjadi campuran bahan bakar pada minyak solar. KP. Orca 02 diwajibkan menggunakan B20 selama operasi sering dilakukan pergantian saringan filter catride sehingga dilakukannya penanganan khusus di KP. Orca 02. Berdasarkan masalah tersebut penulis tertarik untuk meneliti atau mengkaji tentang analisa penggunaan B20 dalam kinerja sistem bahan bakar di KP. Orca 02.

\section{METODE PENELITIAN}

Metode pengumpulan data penelitian yang digunakan dalam penelitian ini adalah :

1. Metode Obeservasi

Melakukan pengamatan langsung terhadap objek yang penulis akan teliti. Kegiatan dilakukan secara langsung dilapangan.

2. Metode Wawancara

Mewawancarai pihak-pihak yang berkompeten yaitu KKM dan Perwira KP. Orca 02

3. Pengujian Lab

Pengujian laboratorium kandungan B20 sebelum masuk purifier dan hasil keluaran purifier, perbedaan parameter sendimen dari 0,006\%wt ke 0,005\%wt, dan kadar condradson carbon residu dilakukan di PT. Petrolab Service.

Setelah melakukan pengolahan data, data-data yang terkumpul segera dilakukan analisa data secara komparatif dengan tujuan untuk mengkaji data hasil yang di peroleh selama di lapangan dibandingkan dengan standar literatur yang ada.

\section{HASIL DAN PEMBAHASAN}

Kebijakan penggunaan B20 di KP.Orca 02 Penggunaan Biosolar (B20) di KP Orca 02 berdasarkan ketentuan ini penggunaan Biosolar (B20) mengacu kepada :

a. Peraturan Menteri ESDM nomor 41 tahun 2018.

b. Peraturan Menteri ESDM nomor 25 tahun 2013.

c. Keputusan Direktur Jenderal Minyak dan Gas Bumi nomor 28.K/10.DJM.T/2016. 
Buletin JSJ, 1 (2), 2019, 81-77

Available online di: http://ejournal-balitbang.kkp.go.id/index.php/JSJ/index

\section{Implementasi Penggunaan Bahan Bakar (B20) Di KP.Orca 02}

Biosolar (B20) atau bahan bakar solar dengan campuran fatty acid methyle ester (FAME) 20\% pada masa peralihan (HSD) ke (B20) implementasi penggunaan B20 tanpa dilakukannya penanganan khusus pada pengisian dan penyimpanan.

Penggunaan biosolar (B20) pada KP.Orca 02 digunakan untuk Main Engine (M/E) dan Auxlary Engine (A/E), pada awal penggunaan (B20) berpengaruh terhadap sistem bahan bakar pada $(\mathrm{M} / \mathrm{E})$. terutama pada penggunaan filter catridge, yang biasanya interval waktu penggantian normalnya 250 jam kerja mesin sedangkan fakta dilapangan 10 jam kerja sudah dilakukan penggantian karena menyebabkan fuel press pada $(\mathrm{M} / \mathrm{E})$ rendah maka dilakukan penggantian filter catridge.

\section{Penyimpanan B20 di KP. Orca 02}

Pada saat perubahan penggunaan bahan bakar (HSD) menjadi (B20) pada KP.Orca 02 dilakukan dengan cara mencampurkannya secara langsung dan tanpa dilakukannya cleaning terhadap tangki utama dan tangki harian terlebih dahulu.Sedangkan menurut (Restituta, dkk. 2018) penggunaan (B20) memerlukan penanganan khusus, meliputi :

1. Melakukan tank cleaning secara teratur dan berkala.

2. Melakukan pemeriksaan kebersihan dasar tangki, strainer/filter pompa.

3. Melakukan tindakan untuk mengurangi kadar air dalam tangki.

Menurut (Restituta, dkk. 2018) pada tahap awal pemakaian campuran biodiesel (B20), sifat pelarut (solvency) biodiesel dengan sendirinya akan membersihkan seluruh deposit atau endapan pada tangki maupun saluran bahan bakar yang menyebabkan tersumbatnya saluran filter bahan bakar. Sistem bahan bakar common rail, meliputi filter catridge, fuel filter, high pressure pump, injector, sedangkan spare part yang digunakan pada KP. Orca 02 adalah Original Manufacturer Equipment (OME) sehingga penggantian spare part yang mahal menyebabkan biaya beban perawatan yang sangat mahal.

Tabel 1. Hasil Lab Kandungan Pada Filter Catridge (PT. Petrolab Services. 2019)

\begin{tabular}{ccccc}
\hline No & Parameter & Unit & Metoda & Hasil \\
\hline 1. & Kandungan Logam: & $\mathrm{mg} / \mathrm{l}$ & & \\
& $-\mathrm{Mg}$ & $\mathrm{mg} / \mathrm{l}$ & ASTMD 5185-13el & 2 \\
& $-\mathrm{Ca}$ & $\mathrm{mg} / \mathrm{l}$ & & 2 \\
& $-\mathrm{Zn}$ & $\% w t$ & ASTMD 473-07 & 0,168 \\
2. & Sedimen & & (Reapproved 2017)el & \\
\hline
\end{tabular}

Kandungan yang menempel pada filter catridge dari laporan hasil pengujian kandungan pada residu yang menempel di filter catridge berupa sediment dan metal content berupa magnesium, calcium, zn. Karena sifat kimia dari B20 itu sendiri dapat melarutkan kotoran pada tangki. B20 memiliki visikositas lebih kental mengakibatkan akumulasi kontamina antara gliserida, sendimen, metal conten, dan pada biosolar terdapat air, sehingga menyebabkan penyumbatan pada filter catridge dan interval waktu penggantian filter catridge lebih cepat. Suharto (2017), mengatakan bahwa salah satu kendala yang di temukan adalah karakteristik biosolar mempunyai visikositas 10 sampai 20 kali lebih tinggi jika di bandingkan dengan bahan bakar diesel fosil. 
Buletin JSJ, 1 (2), 2019, 88-101

Available online di: http://ejournal-balitbang.kkp.go.id/index.php/JSJ/index

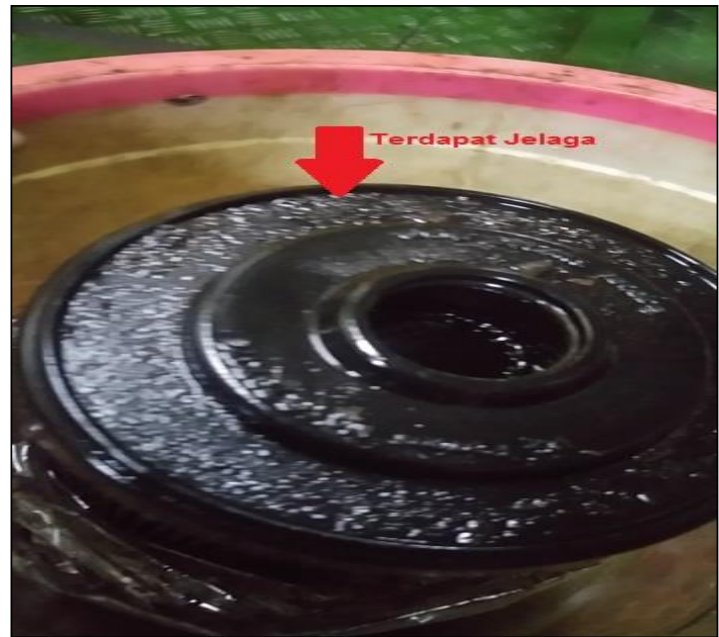

(a)

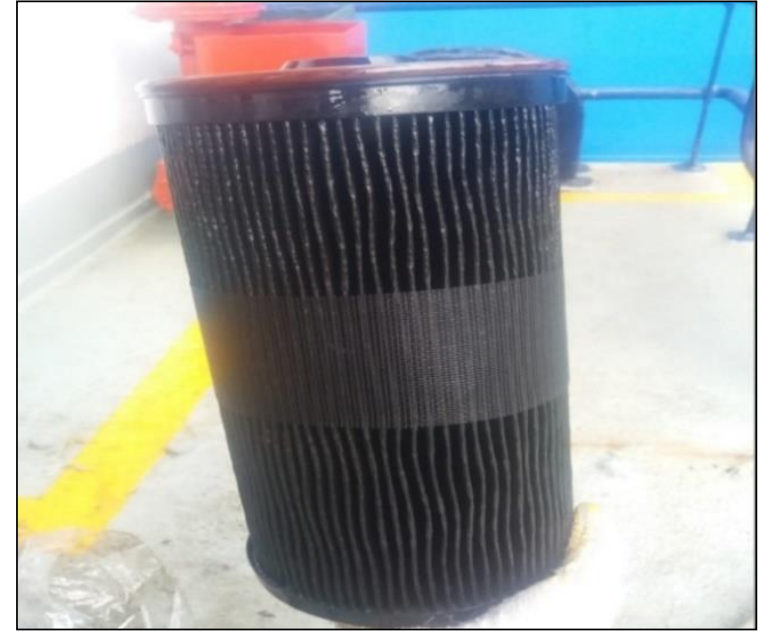

(b)

Gambar 1. Performan filter catridge setelah digunakan (a) Filter catridge terdapat jelaga

(b) Filter catridge hitam pekat

\section{Efek Terhadap High Pressure Pump}

High pressure pump berfungsi sebagai mendistribusi bahan bakar bertekanan tinggi ke injector, kotoran - kotoran yang menyumbat pada fillter catridge dan fuel filter, sehingga terjadinya tekanan bahan bakar rendah, dan sensor pada mesin akan merespon mati jika tekanan bahan bakar melebihi batas minimal toleransi. Pada monitor local operating panel yang terdapat pada engine control room, pressure fuel menunjukan warna biru sejajar dengan warna kuning sensor menunjukan segera dilakukannya penggantian fuel filter dan fillter catridge jika tidak dilakukannya penggantian menyebabkan kerja high pressure pump berat dan mesin akan otomatis mati karena melebihi batas minimal.

\section{Efek Terhadap Injector}

Injector berfungsi untuk mengkabutkan bahan bakar menuju ke ruang pembakaran, jika kotorankotoran tidak tersaring dengan baik pada fillter catridge dan fuel filter akan menyebabkan kotoran yang tidak tersaring mengakibatkan performa mesin turun karena tekanan bahan bakar di injector tidak normal, jika kondisi ini dibiarkan kerusakan bertambah parah dan akan dilakukan penggantian pada injector.

\section{Tindakan Penanganan Penggunaan (B20) Di KP. Orca 02}

Setelah sering terjadinya penggantian filter catridge pada KP. Orca 02 Direktur Pemantauan dan Operasi Armada Direktorat Jenderal Pengawasan Sumber Daya Kelautan dan Perikanan melakukan tindakan dengan cleaning tangki pada saat perawatan tahunan kapal docking di PT.DUMAS Surabaya. Dan juga dilakukan pemasangan purifier. 
Buletin JSJ, 1 (2), 2019, 81-77

Available online di: http://ejournal-balitbang.kkp.go.id/index.php/JSJ/index

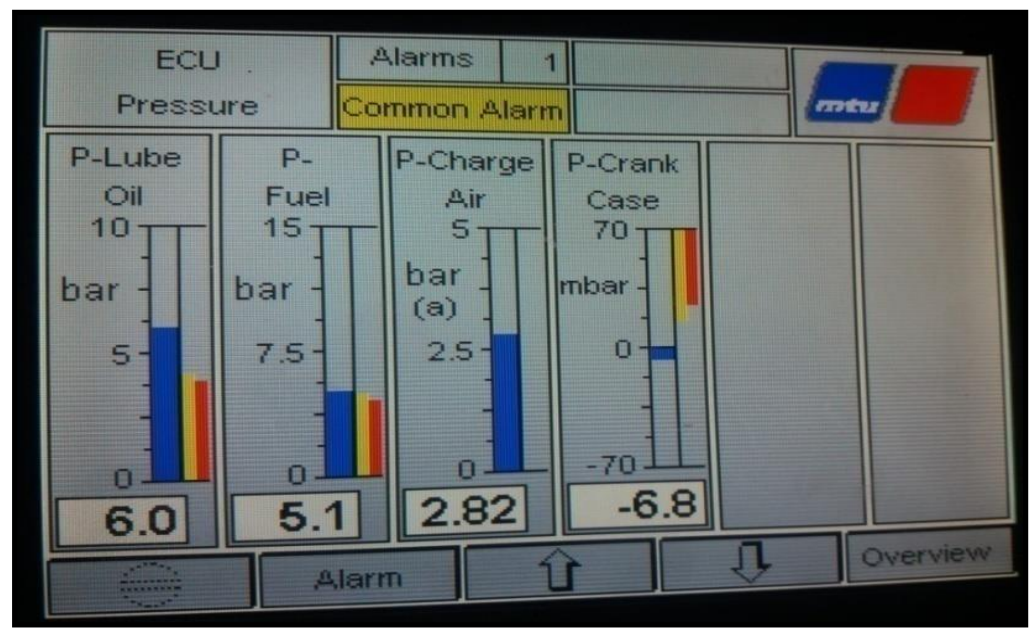

Gambar 2. Local operating panel.

\section{Cleaning Pada Tangki}

Cleaning pada tangki adalah tindakan penanganan khusus yang dilakukan oleh KP. Orca 02 tangki pada KP.Orca 02 terdiri dari tanki utama dan tangki harian

\section{Pemasangan Purifier}

Purifier berfungsi memisahkan bahan bakar dari kotoran padat (lumpur) agar bahan bakar yang digunakan dalam kondisi optimal dan tidak menggangu proses kerja mesin. Penulis melakukan penelitian B20 sebelum dan sesudah masuk mesin purifier. Parameter pada bahan bakar (B2O) yang penulis ambil adalah water conten, cetane index, condradson carbon residu $10 \%$ distilate residu, dan sulphur content, sendiment.

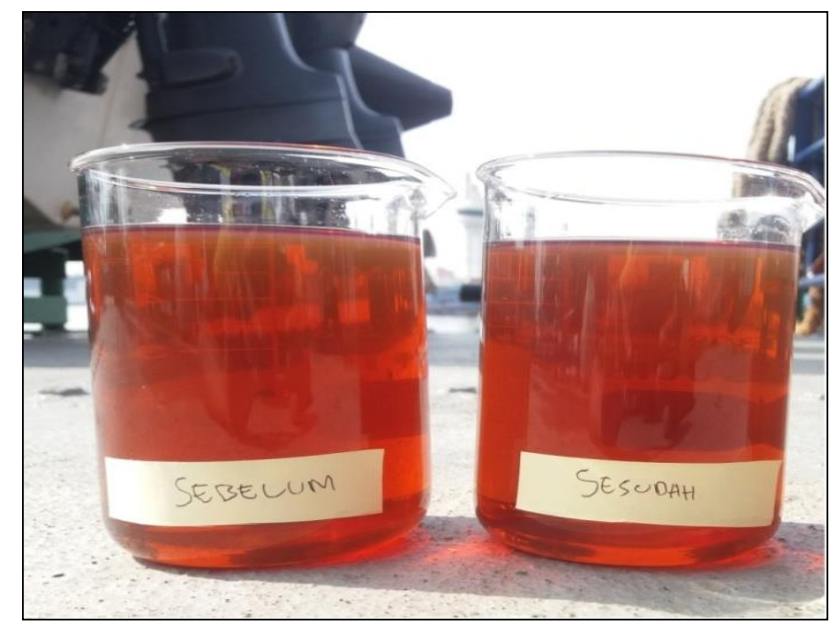

Gambar 3. Sample hasil purifier.

Hasil uji lab bahan bakar B20 sebelum masuk purifier, 1 dari 5 parameter yang diambil tidak dalam kondisi standar, hasil dari condradson carbon residu on $10 \%$ distilate residu adalah $0,21 \%$ wt melebihi dari ketentuan max. 0,1\%wt ketika carbon residu melebihi batas standar akan menggangu kinerja mesin. Kadar residu karbon menunjukkan tendensi pembentukan jelaga (cokes). Tingkatan residu karbon tergantung pada jumlah asam lemak bebas, jumlah gliserida, 


\section{Buletin JSJ, 1 (2), 2019, 88-101}

Available online di: http://ejournal-balitbang.kkp.go.id/index.php/JSJ/index

dan jumlah logam alkali sebagai katalis yang sudah berbentuk sabun. Kadar residu karbon harus kecil karena fraksi hidrokarbon ini akan menyebabkan penumpukan residu karbon dalam ruang pembakaran, akibatnya, kinerja mesin berkurang (Restituta, dkk. 2018).

Tabel 2. Hasil Uji Lab B20 Sebelum Masuk Purfier (PT. Petrolab Service. 2019)

\begin{tabular}{|c|c|c|c|c|c|}
\hline No & Parameter & Unit & Metoda & Hasil & Type \\
\hline 1. & $\begin{array}{l}\text { Water content by Karl } \\
\text { Fische }\end{array}$ & $\mathrm{mg} / \mathrm{l}$ & ASTMD 6304-07 & 182 & Max.500 \\
\hline 2. & Celane Index & - & ASTMD 4773-10 & 61 & Min.45 \\
\hline 3. & $\begin{array}{l}\text { Condrason carbon } \\
\text { residu on } 10 \%\end{array}$ & $\% w t$ & ASTMD 189-06 & 0,21 & Max.01 \\
\hline 4. & Sulphur content & $\% w t$ & ASTMD 5185-13 & 0,07 & $\begin{array}{c}\text { Max.0,25 } \\
\text { (ASTMD } \\
\text { 4294) }\end{array}$ \\
\hline 5. & Sediment & $\% w t$ & ASTMD 473-07 & 0,006 & Max. 0,01 \\
\hline
\end{tabular}

\section{.Hasil Uji Lab B20 Setelah Purifier}

Setelah masuk purifier dan dilakukan proses pembersihan di purifier bahan bakar B20 mengalami perubahan pada parameter sediment mengalami perubahan dari $0,006 \%$ wt ke $0,005 \%$ wt dan parameter lainnya tidak mengalami perubahan. Pemasangan purifier membantu pembersihan bahan bakar sebelum menuju ke tangki harian agar kontaminan kotoran biosolar dapat berkurang dan tidak menyebabkan penyumbatan sehingga kualitas biosolar baik. Dan pemasangan purifier tidak berpengaruh pada kualitas bahan bakar yang diakibat reaksi oksidasi dari unsur kima biosolar tersebut

Tabel 3. Hasil Uji Lab B20 Setelah Purifier (Sumber : Pt. Petrolab Service, 2019)

\begin{tabular}{|c|c|c|c|c|c|}
\hline No & Parameter & Unit & Metoda & Hasil & Type \\
\hline 1. & $\begin{array}{l}\text { Water content by Karl } \\
\text { Fische }\end{array}$ & $\mathrm{mg} / \mathrm{l}$ & ASTMD 6304-07 & 182 & Max.500 \\
\hline 2. & Celane Index & _ & ASTMD 4773-10 & 61 & Min.45 \\
\hline 3. & $\begin{array}{l}\text { Condrason carbon } \\
\text { residu on } 10 \%\end{array}$ & $\% w t$ & ASTMD 189-06 & 0,21 & Max.01 \\
\hline 4. & Sulphur content & $\% w t$ & ASTMD 5185-13 & 0,07 & $\begin{array}{c}\text { Max.0,25 } \\
\text { (ASTMD } \\
4294)\end{array}$ \\
\hline 5. & Sediment & $\% w t$ & ASTMD 473-07 & 0,005 & Max. 0,01 \\
\hline
\end{tabular}

Menurut (Restituta, dkk. 2018) kandungan air dapat menyebabkan turunnya panas pembakaran, pembentukan busa, dan meningkatkan korosivitas material, sehingga dibatasi maksimal 500 ppm. Kandungan sulphur conten dalam kondisi normal, sulphur berpengaruh pada emisi gas buang, dimana gas buang akan berpengaruh terhadap lingkungan, keunggulan pemakaian biosolar adalah lebih ramah lingkungan.

\section{Analisa Penggunaan Biosolar B20 Terhadap Filter Catridge dan Fuel Filter}

Pergantian pemakaian bahan bakar pada KP. Orca 02 dari (HSD) ke biosolar (B20) tanpa dilakukanya cleaning menyebabkan sering dilakukannya pergantian filter catridge. Maka dilakukanlah penaganan maka dari itu dilakukan penanganan khusus berupa cleaning pada tangki dan dipasangkannya purifier. 


\section{Buletin JSJ, 1 (2), 2019, 81-77}

Available online di: http://ejournal-balitbang.kkp.go.id/index.php/JSJ/index

\section{Perbandingan Pemakaian Filter Catridge}

Penulis melakukan perbandingan pemakaian filter catridge sebelum dan sesudah dilakukannya penanganan khusus. Data dibawah menunjukan dampak pada filter catridge.

Tabel 4. Pemakaian Filter Catridge

\begin{tabular}{cccccc}
\hline Uraian & Trip & $\begin{array}{c}\text { Jam Kerja } \\
\text { (jam) }\end{array}$ & RPM & $\begin{array}{c}\text { Pemakaian } \\
\text { filter catridge }\end{array}$ & $\begin{array}{c}\text { Rata-rata } \\
\text { pemakaian }\end{array}$ \\
\hline Sebelum & 1 & 25 & 1.600 & 6 & \\
penanganan khusus & 2 & 46 & 1.600 & 6 & 9,75 \\
& 3 & 34 & 1.500 & 12 & \\
\hline Setelah & 4 & 57 & 1.400 & 15 & \\
penanganan khusus & 5 & 81 & 1.600 & 4 & 2,5 \\
& 7 & 90 & 1.600 & 2 & \\
\hline
\end{tabular}

Dalam tabel diatas diketahui pemakaian filter catridge sebelum pemasangan purifier dan setelah dilakukanya cleaning pada tangki serta dipasangkannya purifier mengalami penurunan yang signifikat. Dan mendapatkan hasil grafik pemakaian filter catridge sebagai berikut.

Tabel 5. Interval Waktu Penggantian Filter Catridge

\begin{tabular}{cccccc}
\hline Uraian & Trip & $\begin{array}{c}\text { Jam Kerja } \\
\text { (jam) }\end{array}$ & $\begin{array}{c}\text { Pemakaian Filter } \\
\text { Catridge }\end{array}$ & $\begin{array}{c}\text { Rata-rata } \\
\text { Pemakaian } \\
\text { filter } \\
\text { catridge }\end{array}$ & $\begin{array}{c}\text { Interval } \\
\text { Waktu } \\
\text { Penggantian }\end{array}$ \\
\hline Sebelum & 1 & 25 & 6 & & \\
penanganan khusus & 2 & 46 & 6 & 9,75 & 16,61 \\
& 3 & 34 & 12 & & \\
penanganan khusus & 4 & 57 & 15 & & 131,2 \\
& 5 & 81 & 4 & & \\
\hline
\end{tabular}

Tabel 6. Pemakaian Fuel Filter

\begin{tabular}{cccccc}
\hline Uraian & Trip & $\begin{array}{c}\text { Jam Kerja } \\
\text { (jam) }\end{array}$ & RPM & $\begin{array}{c}\text { Pemakaian } \\
\text { Fuel Filter }\end{array}$ & $\begin{array}{c}\text { Rata-rata } \\
\text { Pemakaian }\end{array}$ \\
\hline Sebelum & 1 & 25 & 1.600 & 0 & \\
penanganan khusus & 2 & 46 & 1.600 & 2 & 1,5 \\
& 3 & 34 & 1.500 & 2 & \\
\hline Setelah & 4 & 57 & 1.400 & 2 & \\
penanganan khusus & 5 & 81 & 1.600 & 0 & 1,5 \\
& 6 & 90 & 1.600 & 0 & \\
\hline
\end{tabular}

Dalam tabel diatas diketahui pemakaian fuel filter sebelum dan sesudah dilakukannya penanganan khusus tidak mengalami perubahan. 
Buletin JSJ, 1 (2), 2019, 88-101

Available online di: http://ejournal-balitbang.kkp.go.id/index.php/JSJ/index

\section{Pemakaian Fuel Filter}

Penggantian bahan bakar dari HSD ke biosolar (B20) berdasarkan data diatas tidak terlalu berpengaruh terhadap fuel filter karena pemakaian fuel filter masih normal. Dalam jumlah penggantian fuel filter sebelum dan sesudah penanganan khusus tidak ada perubahan, tetapi berdasarkan interval waktu jam kerja terdapat perbedaan. Berdasarkan hasil analisa interval waktu penggantian fuel filter terdapat peningkatan waktu penggantian setelah dilakukannya penanganan khusus yang semula 108 Jam menjadi 218,6 Jam.

Tabel 7. Interval Waktu Penggantian Fuel Filter

\begin{tabular}{cccccc}
\hline Uraian & Trip & $\begin{array}{c}\text { Jam Kerja } \\
\text { (jam) }\end{array}$ & $\begin{array}{c}\text { Pemakaian Filter } \\
\text { Catridge }\end{array}$ & $\begin{array}{c}\text { Rata-rata } \\
\text { Pemakaian } \\
\text { Fuel Filter }\end{array}$ & $\begin{array}{c}\text { Interval } \\
\text { Waktu } \\
\text { Penggantian } \\
\text { (jam) }\end{array}$ \\
\hline Sebelum & 1 & 25 & 0 & & \\
penanganan khusus & 2 & 46 & 2 & 1,5 & 108 \\
& 3 & 34 & 2 & & \\
penanganan khusus & 4 & 57 & 2 & 1,5 & 218,6 \\
& 5 & 81 & 2 & & \\
\hline
\end{tabular}

\section{Perbandingan Pemakaian Fuel Filter Dalam Aspek Ekonomi}

Penghematan pemakaian fuel filter selama uji coba mengalami perubahan yang siginfikan setelah dilakukannya proses cleaning pada tangki dan pemasangan purifier, penghematan berdasarkan aspek pada uji coba yang dilakukan tidak berdampak.

\section{Faktor-Faktor Penyebab Sering Dilakukan Penggantian Filter Catridge dan Fuel Filter}

Terdapat beberapa faktor yang menyebabkan sering dilakukannya penggantian filter catridge dan fuel filter karena sifat dari unsur nabati (FAME). Menurut Restituta, dkk. (2018) tata kelola bahan bakar campuran biosolar tidak dapat disamakan dengan penanganan bahan bakar minyak solar murni, mengingat adanya sifat fisika dan kimia, serta karakteristik biosolar tertentu yang dengan mudah terdegradasi akibat kontaminasi air, lumpur/sedimen, mikroba, dan senyawa lainnya.

\section{Faktor Internal}

Faktor internal adalah faktor yang berasal dari dalam kapal itu sendiri, berikut ini beberapa faktor internal :

a) Tangki baan bakar di KP Orca 02; Faktor ini disebabkan saat penggantian bahan bakar biosolar B20, tidak dilakukan penangganan khusus pada tangki yaitu dilakukan cleaning karena pencampuran (HSD) dan (B20) pada KP.Orca 02 tidak dilakukan cleaning terlebih dahulu karena terdapat kerak-kerak dan kotoran pada tangki yang tidak terlarut dalam pemakaian (HSD), sedangkan (B20) memiliki sifat pelarut sehingga menyebabkan kotoran bisa berupa endapan lumpur dan korosi pada tangki bahan bakar terbawa ke dalam sistem bahan.

b) Pendiaman bahan bakar pada tangka; Pendiaman bahan bakar pada tangki dapat menyebabkan penurunan kualitas bahan bakar, dan memiliki pengaruh terhadap stabilitas oksidasi, angka asam, viskositas kinematik, karena terdapat reaksi kimia. 
Available online di: http://ejournal-balitbang.kkp.go.id/index.php/JSJ/index

c) Pipa distribusi bahan bakar; Pada pipa-pipa terdapat kotoran-kotoran dan kerak bekas pemakaian (HSD) yang terbawa ke dalam sistem distribusi karena sifat pelarut dari biosolar (B20) sehingga meningkatkan kontaminasi kotoran pada bahan bakar

\section{Faktor Eksternal}

Faktor eksternal adalah faktor yang diakibatkan oleh luar, berikut ini beberapa faktor:

a) Faktor cuaca; Pada awal penggunaan (B20) yang langsung dilakukan pencampuran dalam tangki dan kondisi tangki yang belum dilakukannya cleaning masih terdapat kerak-kerak dan kotoran, pada saat KP. Orca 02 pada saat melakukan operasi dengan cuaca berombak cuaca buruk atau berombak sehingga isi dalam tangki terkoyak sehingga kotoran atau endapan tercampur sehingga masuk masuk ke sistem bahan bakar;

b) Pengisian bahan bakar kapal tanker; Pada KP. Orca 02 biasanya melakukan pengisian melalui tanker dan mobil tangki minyak, Pengisian bahan bakar dari tanker juga mempengaruhi karena kondisi tangki pada tanker tersebut terdapat kotoran berupa endapan dan koros yang terbawa pada saat pemindahan bahan bakar dari kapal tanker ke KP.Orca 02.

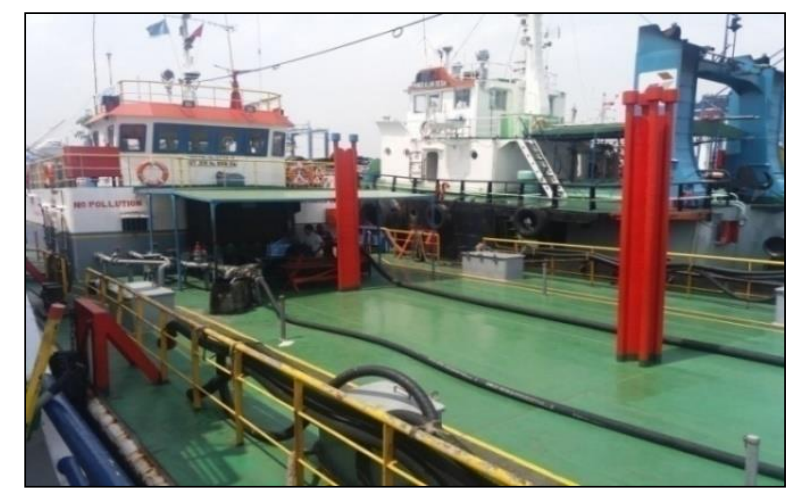

Gambar 4. Pengisian kapal tongkang

c) Pengisian bahan bakar tangki mobil; Pengisian bahan bakar dari tangki mobil Selain pengisian bahan bakar dengan kapal tanker pada KP.Orca 02, pengamatan yang penulis lakukan pada tangki mobil bahan bakar terdapat sedikit kotoran yang menempel pada dinding hal ini berpengaruh karena terdapat kotoran yang terbawa ketika distribusi bahan bakar dari tangki mobil ke tangki utama KP.orca 02.

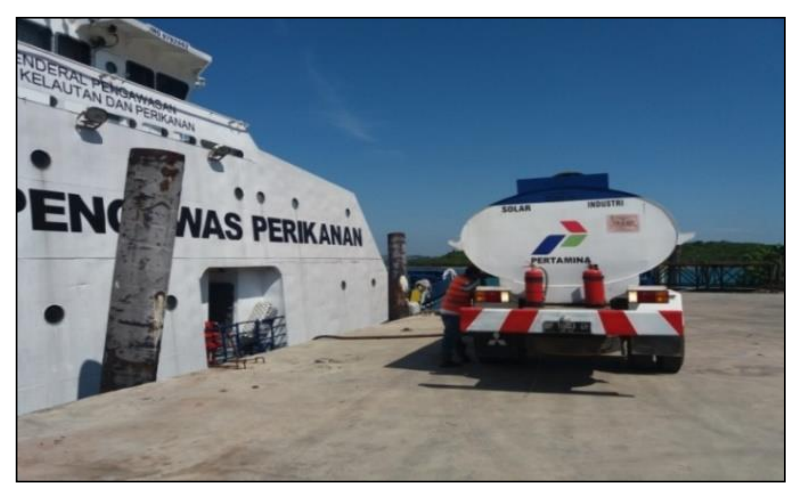

Gambar 5. Pengisian menggunakan tangki mobil 


\section{Buletin JSJ, 1 (2), 2019, 88-101}

Available online di: http://ejournal-balitbang.kkp.go.id/index.php/JSJ/index

d) Selang distribusi bahan bakar; Pada saat pengisian bahan bakar selang bahan bakar yang biasa digunakan jarang dilakukan pembersihan dan mengakibatkan berpengaruh karena dapat membawa kotoran yang terdapat pada selang tersebut pada saat sistem distribusi bahan bakar ke tangki KP. Orca 02. Selang yang digunakan berbahan karet menurut (Restituta, dkk. 2018) biosolar dapat merembes kedalam material karet alami dan sintesis seperti nitrit (tergantung komposisi kimia, konstruksi dan aplikasi) mungkin akan mengalami kerusakan, khusus untuk karet alami tidak disarankan untuk aplikasi biosolar.

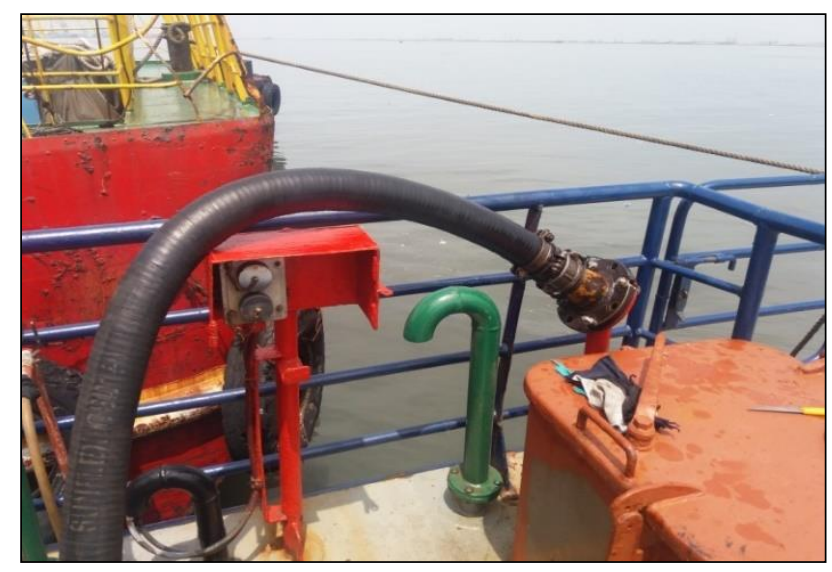

Gambar 6. Pengisian bahan bakar dengan selang

\section{KESIMPULAN DAN SARAN}

\section{Kesimpulan}

Berdasarkan uraian hasil dan pembahasan di atas, penulis dapat mengambil kesimpulan sebagai berikut :

1. Pemakaian B20 pada KP.Orca 02 tidak dilakukan penanganan khusus cleaning pada tangki dan hanya mencampurkan langsung ke tangki sehingga memiliki efek penggunaan pada sistem bahan bakar terutama pada filter catridge karena sifat pelarut (B20) yang dapat melarutkan kerak-kerak dan kotoran pada tangki sehingga kerak dan kotoran menyebabkan penyumbatan pada filter catridge.

2. Penanganan khusus setelah terjadinya pemakaian filter catridge yang lebih dari biasanya pada KP. Orca 02 melakukan tindakan cleaning tangki dapat mengurangi pemakaian secara signifikan, dan pemasangan mesin purifier hanya bersifat membantu membersihkan kotoran tetapi tidak dapat mengatasi penurunan kualitas bahan bakar, berdasarkan hasil uji lab (B20) pemasangan mesin purifier dari 5 parameter yang di uji, hanya 1 parameter yang mengalami perubahan semula $0,006 \%$ wt menjadi $0,005 \%$. Hasil uji lab (B20) parameter condradson carbon residu on $10 \%$ yaitu $0,21 \%$ wt melebihi nilai typical max $0,1 \%$ wt dimana tingkatan condradson carbon residu memiliki hubungan dengan jumlah asam lemak bebas, jumlah gliserida, dan jumlah logam alkali, jika kadar condradson carbon residu tinggi bisa disimpulkan jumlah asam lemak bebas, jumlah gliserida dan jumlah logam alkali juga tinggi yang diakibatkan terjadinya penurunan kualitas bahan bakar pada tangki.

3. Perlakuan penangan khusus berpengaruh terhadap pemakaian filter catridge mengalami penurunan $74,7 \%$ dan perubahan interval waktu jam kerja semula 16,61 Jam menjadi 131,2 Jam sehingga mempengaruhi pemakaian filter catridge yang semula pemakaian 39 filter 


\section{Buletin JSJ, 1 (2), 2019, 81-77}

Available online di: http://ejournal-balitbang.kkp.go.id/index.php/JSJ/index

catridge dengan total jam kerja 162 jam menjadi 10 filter catridge dengan total jam kerja 328 jam dan dalam aspek ekonomi yang semula Rp 40.000.000 menjadi Rp 156.000.000 menghemat pemakaian Rp 116.000.000., sedangkan pada fuel filter hanya mengalami perubahan interval waktu jam kerja yang semula 108 Jam menjadi 202,6 Jam.

4. Faktor-faktor yang paling berpengaruh adalah pada kondisi tangki pada kapal karena sifat kima dari B20 yang dapat melarutkan kotoran pada tangki sehingga harus di perhatikan kebersihan tangki.

\section{Saran}

Berdasarkan pengamatan yang telah dilakukan mengenai analisa penggunaan biosolar (B20) terhadap kinerja sistem bahan bakar KP. Orca 02 selama penulis praktik maka saran yang diberikan adalah :

1. Penggunaan biosolar (B20) memiliki penanganan khusus yang berbeda dari penggunaan (HSD) jadi harus melakukan penanganan khusus ketika menggunakan bahan bakar (B20) mempelajari sifat dan karakteristik dari (B20), mempelajari petunjuk penggunaan bahan bakar yang di sarankan orginal equitmen manufacturer.

2. Penanganan khusus cleaning tangki dan pemasangan purifier tidak dapat mengatasi penurunan kualitas bahan bakar yang terdapat pada penyimpanan jadi disarankan untuk meminimalisir reaksi kimia (B20) dengan menjaga kondisi temperatur dan kondisi tangki harus full karena B20 mudah teroksidasi serta tidak melakukan pendiaman bahan bakar lebih dari 3 bulan, melakukan pengecatan tangki dengan cat reflector pada bagian luar tangki.

3. Selalu mendrain tangki agar membuang air dan endapan pada tangki induk dan melakukan cleaning tangki induk setiap 3 bulan.

4. Meminimalisir faktor penyebab masuknya kotoran pada tangki induk serta mengganti penggunaan material logam dan elastomer yang tidak cocok dengan penggunaan (B20).

\section{DAFTAR PUTAKA}

Apriwi L.N. 2015. Diklat Kuliah Bioenergi Biodesel Dan Bioetanol. Universitas Udayan. Hal 1-35

Barokah., Piet H.K., dan S. Tappy. 2015. Purifier Bahan Bakar.Dalam Menunjang Kelancaran Operasional Permesinan. Buletin Maatric. Hal 23-28.

Barus R.B. 2018. Petunjuk Teknis Penanganan Dan Penyimpanan Campuran Biodisel 20\% pada Aplikasi Unit Alat Berat Di Pertambangan Mineral Dan Batu Bara. Direktorat Bioenergi Kementrian Energy Dan Sumber Daya Mineral. Jakarta. hal.87

Conceicao, M.M. dkk. 20105. Theological Bahavior of Castor Oil Biodiesel. Energy \& Fuels. Hal $1-19$

Flisch, S. 2014. Quentitation Of Aging Products Formed In Biodiesel During The Rancimat Accelerate Oxidation Test. Energy \& Fuels Volume 28. Hal 5849-5856.

Hendra D., wibowo S., dan wibisono H S. 2018.Biodiesel Dari Beberapa Jenis Tanaman Hutan.IPB Press. Bogor. 79 Hal.

M.Mittelbach., \& S. Gangl. 2001. Long Storage Stability Of Biodiesel Made From Rapeseed And Used Frying Oil.Agromedia Pustaka. Jakarta. 128 Hal. 


\section{Buletin JSJ, 1 (2), 2019, 88-101}

Available online di: http://ejournal-balitbang.kkp.go.id/index.php/JSJ/index

Rahayu M. 2005. Teknologi Proses Produksi Biodiesel. Prospek Pengembangan Bio-Fuel Sebagai Substansi Bahan Bakar Minyak. Hal 17-28.

Soharto I. 2017. Bioteknologi Dalam Bahan Bahan Bakar Nonfosil. ANDI. Yogyakarta. 274 hal.

Waluyo A., Saksono Puji., dan Gunawan. 2017. Analisis Perbandingan Bahan Bakar Solar Dan Biodiesel B20 Terhadap Performasi Engine Volvo D9B 380. Seminar Nasional Inovasi Dan Aplikasi Teknologi Di Industri.

Wibowo C.S., 2016. Pengaruh Kondisi Penyimpanan Terhadap Stabilitas Oksidasi Bahan Bakar Jenis Biodisel (B-100), Biosolar (B-20) Dan Minyak Solar Murni (B-0). Lembaran Publikasi Minyak dan Gas Bumi Vol. 50. Hal 196-205 